\title{
Bruno Petey-Girard, Quelques lecteurs français $d u$ «De curialium miseriis»
}

\section{Filippo Fassina}

\section{Q OpenEdition}

1 Journals

\section{Edizione digitale}

URL: http://journals.openedition.org/studifrancesi/8852

DOI: $10.4000 /$ studifrancesi.8852

ISSN: 2421-5856

\section{Editore}

Rosenberg \& Sellier

\section{Edizione cartacea}

Data di pubblicazione: 1 octobre 2008

Paginazione: 438

ISSN: 0039-2944

\section{Notizia bibliografica digitale}

Filippo Fassina, «Bruno Petey-Girard, Quelques lecteurs français du «De curialium miseriis»», Studi Francesi [Online], 155 (LII | II) | 2008, online dal , consultato il 14 janvier 2021. URL: http:// journals.openedition.org/studifrancesi/8852 ; DOI: https://doi.org/10.4000/studifrancesi.8852

Questo documento è stato generato automaticamente il 14 janvier 2021.

\section{(c) (i) (9)}

Studi Francesi è distribuita con Licenza Creative Commons Attribuzione - Non commerciale - Non opere derivate 4.0 Internazionale. 


\title{
Bruno Petey-Girard, Quelques lecteurs français $d u$ «De curialium miseriis»
}

\author{
Filippo Fassina
}

\section{NOTIZIA}

BRUNO PETEY-GIRARD, Quelques lecteurs français du «De curialium miseriis», in Pio II umanista europeo, «Atti del XVII Convegno Internazionale (Chianciano-Pienza 18-21 luglio 2005)», a cura di Luisa SECCHI TARUGI, Firenze, Franco Cesati Editore, 2007, pp. 637-651.

1 L'A. fornisce un quadro dettagliato del successo e della diffusione in Francia della De curialium miseriis epistola, nota anche come Tractatus pulcherrimus Enee Sylvi sive Pii II, de curialium miseria di Enea Silvio Piccolomini. L'opera - una lettera inviata nel 1444 a Johannes von Eych, segretario di Federico II - si caratterizza come un trattatello che ha come argomenti il disprezzo della vita aulica e un modello di vita basato sulla cultura laica, modello nel quale convivono le Sacre Scritture e i classici latini e greci. La mancanza di traduzioni francesi di questa lettera non implica che essa non circolasse e non fosse oggetto di lettura e di citazione da parte dei letterati d'oltralpe. Il presente studio parte da questa premessa per analizzare l'influsso del De curialium sulla cultura francese. In primo luogo, viene citata la lettera «A Messieurs les gouverneurs, officiers et serviteurs des Empereurs, Roys et Princes, et toutes gens de Court» di Jean Bouchet, che tuttavia, pur offrendo, in buona sostanza, un adattamento della lettera di Piccolomini, non riconosce alcun debito letterario. L'A. si concentra, invece, su tre trattatisti che citano esplicitamente il De curialium: Jean de l'Espine Du Pont-Allais (Contredictz de songecreux), Pierre Boaistuau (Theatre du Monde) e Gabriel Chappuys (Le Misaule, ou haineux de court). Benché il debito nei confronti del De curialium sia evidente, anche in questi autori la citazione non è mai diretta. L'A. analizza, quindi, i metodi adottati nei singoli testi: mentre Boaistuau inserisce soltanto una breve citazione di Enea Silvio, Du Pont-Allais e Chappuys ne fanno un vero e proprio modello dichiarato e un'autorità che giustifica e avvalora le affermazioni contenute nei loro trattati. Se l'opera di Du Pont-Allais è, però, principalmente esercizio letterario, quella di Chappuys 
offre - secondo l'A. - l'unica reale riflessione sulle tematiche del De curialium e ne presenta una traduzione pressoché letterale. In conclusione, l'influenza del futuro pontefice sul panorama culturale francese è evidente a prescindere dall'ammissione degli autori stessi e conferma l'importanza di un letterato che ha fortemente caratterizzato l'umanesimo europeo. 